Research Article

\title{
Experimental Research on the Measurement of High-Pressure Microflow Based on Momentum Principle
}

\author{
Hua Xia $(\mathbb{D}$, Fuqiang Luo, and Zhong Wang \\ School of Automotive and Traffic Engineering, Jiangsu University, Zhenjiang 212013, China \\ Correspondence should be addressed to Hua Xia; 250930192@qq.com
}

Received 29 April 2021; Revised 27 September 2021; Accepted 11 October 2021; Published 15 November 2021

Academic Editor: Jianguo Wang

Copyright ( $\odot 2021$ Hua Xia et al. This is an open access article distributed under the Creative Commons Attribution License, which permits unrestricted use, distribution, and reproduction in any medium, provided the original work is properly cited.

\begin{abstract}
The fuel injector is an important component of the diesel engine. It has a great influence on the atomization of diesel fuel injection, the formation of mixed gas, and combustion emissions. Due to the current nozzle structure, processing level, and the internal hydraulic conditions of each nozzle, there are certain differences between the injection rules of each hole, and there are few methods to quantify the quality of the injector using mathematical methods in engineering. Based on the principle of spray momentum, this paper measures the injection characteristics of each hole of four five-hole pressureless chamber injectors of the same model and analyzes the circulating fuel injection volume and flow coefficient of each injector and each hole under different working conditions. It is proposed to evaluate the quality of the injector with the average circulating fuel injection volume, average flow coefficient, and nonuniformity as indicators. The test results are as follows: there are differences in the circulating fuel injection volume and flow coefficient between each hole of the same fuel injector. With the increase of the fuel injection pump speed, the average circulating fuel injection volume of each hole differs by $2.8 \%-47.5 \%$, and the average flow coefficient differs by $3.7 \%-30 \%$; as the fuel injection volume increases, the average circulating fuel injection volume of each injector differs $1.8 \%-36 \%$, and the average flow coefficient difference is $2.5 \%-28.7 \%$. The circulating fuel injection volume and flow coefficient of different fuel injectors of the same model are different. With the increase of the fuel injection pump speed, the average circulating fuel injection volume of each injector differs by $3.5 \%-9.6 \%$, and the average flow coefficient differs by $1.4 \%-5.7 \%$; as the fuel injection volume increases, the average circulating fuel injection volume of each injector differs $0.3 \%-5.5 \%$, and the average flow coefficient difference is $2.8-4.2 \%$. The relative flow coefficient of each hole differs from 0 to 0.02 , and the nonuniformity differs from $1.8 \%$ to $16.9 \%$. The relative circulating fuel injection amount of each hole differs from 0.02 to 0.1 , and the nonuniformity differs from $1.1 \%$ to $6.9 \%$. The relative flow coefficient of each hole and its nonuniformity is smaller than the relative circulating fuel injection volume of each hole and its nonuniformity.
\end{abstract}

\section{Introduction}

As a kind of power machinery with high thermal efficiency, diesel engine has been widely used in land transportation, marine transportation, power generation, construction, and other fields. Since diesel engines are mainly powered by burning fossil fuels, pollutant emissions cannot be avoided. With the reduction of fossil fuels, increasing environmental pollution, and the introduction of strict emission regulations in various countries, the requirements for indicators such as diesel engine power, economy, and emissions have become higher and higher.
For diesel engines, the matching between the intake system, fuel injection system, and combustion chamber structure plays a decisive role in the formation of the mixture and the combustion process. The fuel injection system is the most important internal combustion engine and the system with the highest manufacturing and adjustment accuracy. It has a very important impact on the power, economy, emissions and noise, and reliability of the internal combustion engine [1]. As the main component of the fuel supply system to achieve fuel injection, the fuel injector directly affects the overall performance of the diesel engine [2-4]. 
The fuel injector injects fuel into the cylinder, mixes it with air, and burns it. If the local fuel is too rich, the combustion will be incomplete and produce more $\mathrm{CO}$ and $\mathrm{HC}$ soot; if the local mixed gas is thin, the burning speed will slow down and the combustion will be unstable, which will increase the HC. Due to the difference in injector nozzle hole structure, processing level, and hydraulic conditions inside each nozzle hole, the fuel injection rules between the injector and the fuel injector are different, and there are certain differences between the fuel injection rules of each hole. It is easy to cause uneven injection of each hole, resulting in uneven atomization and incomplete combustion of the mixture, which will affect the diesel engine's NOx, HC, PM particle emissions and the diesel engine's power, and economic performance [5-9].

Fuel spray characteristics are an important index for evaluating the quality of fuel injectors. The high-pressure common rail fuel injection system controls the fuel injection pressure, fuel injection timing, and fuel injection volume of the fuel injector through the electronic control unit, thereby adjusting the spray characteristics and changing the heat release law of fuel combustion in the cylinder [10]. At the same time, spray characteristics have a direct impact on the development of fuel spray and the interaction between spray and air in the cylinder.

Therefore, studying the method of measuring fuel injectors, accurately measuring the spray characteristics of diesel fuel injectors, and finding out the rules of fuel injection in each hole have certain practical significance for improving fuel atomization, improving air mixing quality, promoting full fuel combustion, and energy saving and emission reduction [11-13].

In order to accurately measure the spray characteristics of the injector, especially the spray characteristics of each hole, a large number of experts and scholars have conducted research on the test methods, mainly as follows:

(1) Deformation Test Method. In order to study the difference of porous injectors, Marčič [9] proposed a deformation test method. When fuel is injected into the test cavity, the amount of fuel in the test cavity increases sharply, generating a pressure wave, which causes the membrane to deform. The instantaneous fuel injection rate of each hole can be obtained by measuring the deformation of the membrane. The deformation of the film is measured by the strain gauges that make up the Wheatstone bridge. The temperature of the device will rise during the measurement, so temperature compensation for the Wheatstone bridge is required. The deformation test method is more complicated, the steps are cumbersome, the error is large, the system has error, and each hole requires a separate test equipment.

(2) Mass Flow Test Method. A set of interhole mass flow test benches constructed by Payri et al. and Payri et al. are used to measure the mass flow of each hole of the porous injector $[14,15]$. The test bench passes a specially processed splitter device to introduce the spray of each hole into the corresponding siphon device and then obtain the fuel injection volume of each hole. As the fuel flows through the siphon device, part of the fuel will adhere to the wall, the gaseous part of the fuel cannot be completely separated, and it is easy to form oil foam, so the response speed of the test bench is poor. Especially for the measurement of the injection rate of each hole of the electronically controlled fuel injection system that adopts the multiple injection strategy, there are still great difficulties.

(3) Bosch Long Tube Method. In addition, there is the injection rate (Injection Discharge Rate Curve Indicator (IRDCI)) which is the measurement principle. Unlike the traditional Bosch long tube measuring device, it can be used to measure the instantaneous injection rate of a single nozzle on a multihole injector. Payri et al. studied the influence of different fuels on the injection rate, spray momentum, spray characteristics, etc. [16]. Salvador et al., in order to study the influence of the nozzle hole angle of the injector on the injection rate [17], measured the injection rate. The fuel injection rate is used. However, the fuel injection rate indicator can only measure the fuel injection rate of one injection hole at a time, and the fuel injection rate of each hole of the porous injector cannot be measured at the same time. There are still limitations to the analysis of differences.

(4) Calculation Method. Wang et al. combined the pressure-lift method with the calculation method and proposed establishing an injector model by testing the injection pressure and cylinder pressure to calculate the injection pattern (including the single-hole injection rate of the injector) [18]. A diesel engine multihole injector model was established using AMESim calculation software. The outlet pressure of the high-pressure fuel pipe under different working conditions was measured by the simulation test bench. The measurement result was input into the built model as an input signal, and the relevant characteristic curve of the injector was calculated. However, this method uses the compression end cylinder pressure as the injection backpressure in the calculation process, and the actual cylinder pressure is constantly changing during the fuel injection process, so the method needs to be optimized.

(5) Momentum Method. Payri et al. proposed a new measurement method, momentum method, which established the mathematical relationship between the impact force of fuel injection and spray momentum flux; that is, the impact force of fuel injection is numerically equal to the momentum flux of spray [14]. In subsequent studies, Payri et al. used four technical methods to study the difference between the injection characteristics of each nozzle of a diesel engine injector, one of which was to measure the spray momentum flux of the nozzle hole of the 
injector, cavitation in different nozzle holes [14]. Through comparative analysis, it is pointed out that the momentum method is also an effective tool to study the difference of the injection process between the holes of the porous injector. Based on this, Payri et al. [16] built a spray momentum test bench on the common rail fuel injection system and analyzed the influence of different fuels (gasoline and diesel) on spray momentum.

Sangiah and Ganippa applied the spray impact force measurement technology based on the momentum method to measure the spray of the porous injector [19]. The study showed that the measurement distance has no significant effect on the spray flow rate and the flow coefficient (the measurement distances studied in the experiment are, respectively, $0.5 \mathrm{~mm}, 1 \mathrm{~mm}$, and $2 \mathrm{~mm}$ ) and the fluctuation of the fuel injection pressure has a greater impact on the spray momentum but basically has no effect on the average flow coefficient of the nozzle holes. The spray momentum changes with the fluctuation of the fuel injection pressure. There is a certain difference between the law and the average impact force, and it is pointed out that this test method is one of the important tools to study the transient characteristics of the flow inside the nozzle under high rail pressure.

The test research on the difference of the injection regularity of each injector has an important guiding role for the performance optimization and quality control of the fuel injection system. Throughout the domestic and foreign scholars' relevant research on the testing equipment and methods of the injection pattern of each hole, there are the following problems:

(1) The test measurement lacks engineering mathematical characterization and cannot quantify the change law between injector and injector, hole and hole, especially after the injection pressure increases

(2) It is impossible to measure each hole at the same time

(3) There are poor response characteristics, not suitable for the current situation of more and more nozzle holes in the injector

Momentum method has the characteristics of higher test accuracy, higher response characteristics, and high feasibility. It can quantitatively study the instantaneous injection pattern of each hole and the difference between each hole. Spray momentum not only can solve the nozzle mass flow rate and nozzle outlet fuel flow rate, but also has an important influence on the mixture ratio of combustible gas. It has been widely used in the field of fuel injector related research. Because the fuel injector works under dynamic fuel injection pressure $[19,20]$, the dynamic characteristics can more accurately reflect its fuel injection performance [21-23]. However, the application of spray momentum to the quantitative analysis of the difference of the injection characteristics of each hole and the consistency of the injection cycle is rarely involved, and the measurement research of the dynamic spray characteristics of each hole is rarely reported.
Therefore, based on the momentum method, this paper carries out an experimental study on the dynamic spray characteristics of each hole, measures and analyzes 4 injectors of the same model, and compares and analyzes the spray characteristics of each hole. Mathematical statistics are performed on the measurement results, and the injection characteristics, parameter changes, and laws of each nozzle of the injector are pointed out. Combined with the quality analysis of diesel engine high-pressure injection and fuel atomization, the engineering application evaluation method is proposed. It has certain guiding significance for the processing, testing, and evaluation of fuel injectors.

\section{A Brief Introduction to the Experiment}

2.1. Measuring Method. The testing devices of each hole in the injector are built on the traditional pump-pipe-nozzle test bench based on the momentum method. By testing the spray momentum flux of each hole as well as the fuel injection (tested by the piezoelectric sensor fixed above the nozzle VCO), the researchers obtained the injection characteristic of each hole [24-26]. They analyzed those signals mentioned above with DAS.

According to Newton's Second Law of Motion-Force and Acceleration and the law of conservation of momentum, the spray momentum of each hole tested above indicates that

$$
F(t+\tau)=\dot{m}(t) v(t)
$$

According to the Bernoulli equation:

$$
v_{t h}(t)=\sqrt{\frac{2}{\rho} \Delta P(t) .}
$$

The mass flow through the orifice is

$$
\dot{m}(t)=C_{d} \rho A_{0} v_{t h}(t) .
$$

The volume flow rate (the flow rate) calculated by camshaft rotation angle is

$$
V(t)=\frac{1}{6 n} \sqrt{\frac{F(t+\tau) A_{0}}{\rho}} .
$$

According to the integration of camshaft rotation angle, the cycle fuel injection quantity of each orifice is

$$
q=\int \frac{1}{6 n} \sqrt{\frac{F(t+\tau) A_{0}}{\rho}} \mathrm{d} \psi .
$$

In the equations above, $v_{t h}(t)$ (international units are accepted except some labeled ones) is the theoretical transient rate of the holes; $v(t)$ is the actual transient rate; $A_{0}$ is the transversal surface of the hole; $n$ is the camshaft rotation speed ( $\mathrm{r} / \mathrm{min}) ; \rho$ is the fuel density; and $F(t+\tau)$ is the spray momentum (where $t$ represents the time taken by the fuel beam from the hole to the pressure sensor).

Combining (1)-(3), the transient flow coefficient of each hole is 


$$
C_{d i}=\sqrt{\frac{F_{i}(t+\tau)}{2 A_{0} \Delta P(t)}} .
$$

The sums of the transient flow coefficients of each hole phase, together with the total number of holes, are the total transient flow coefficient of the injector:

$$
C_{N d}=\sum_{i=1}^{k} \frac{C_{d i}}{k}
$$

In the equations above, $C_{d i}$ is the transient flow coefficient of the NO.i hole; $C_{N d}$ is the total transient flow coefficient of the injector; $k$ is the total number of holes; and $F_{i}(t+\tau)$ is the spray momentum of the NO.i hole.

\subsection{Test Equipment. The test was carried out in the tradi-} tional pump-pipe-injector injection pump test bed.

The test bed has five important components: power transmission system (motor and coupling); high-pressure fuel supply system (fuel injection pump, high-pressure oil pipe, and fuel injector); low pressure fuel supply system (oil pump and filter); test bed controller (speed control, oil metering, oil temperature, and oil pressure regulation); and the fuel volume measurement system.

The basic parameters of the fuel injection pump are as follows: the diameter of the isobaric oil valve is $5 \mathrm{~mm}$, the diameter of the plunger is $8.5 \mathrm{~mm}$, and the cam lift is $8 \mathrm{~mm}$.

The sensor has the piezoelectric force sensor and clampon pressure sensor clamped. The sensor parameters are shown in Tables 1 and 2. The test system is shown in Figure 1.

2.3. Testing the Injector. The experimental analysis of four injectors of the same model (from N1 to N4) shows that the injection pressure is $25 \mathrm{MPa}$ and the diameters of the $\mathrm{VCO}$, the 5th hole, and the injection nozzle are $0.2 \mathrm{~mm}$. Each orifice position is shown in Figure 2.

\section{Analysis of the Results of the Experiment}

3.1. Circulating Injection Volume and Flow Coefficient of Each Hole of the Injector. Figure 3 shows that, according to equation (4), under different operating conditions of four injectors, there are some changes with the cycle injection quantity of each hole. As the speed becomes faster, the cycle injection quantity of each hole increases, because when the speed is faster, the throttle effect in and out of the orifice is strengthened. Apart from that, the leakage quantity also declines while the cycle injection quantity increases. With the increase in cycle injection quantity, the cycle injection quantity of each hole increases accordingly. As shown in the figures below, the trend appears to be hole $1>$ hole $4>$ hole $3>$ hole $5>$ hole 2 . At the maximum needle valve lift, because the flow area of the needle valve sealing cone is larger than the flow area of the hole, the flow velocity and pressure drop of the fuel in the sealing area between the needle valve and the needle valve seat are small, and cavitation is not easy to occur. When the fuel enters the hole from the sealing cone, the flow rate of the fuel at this position increases suddenly due to the decrease of the flow area and the existence of the pulsation phenomenon. At the same time, the injection pressure suddenly drops and is lower than its saturated vapor pressure, which promotes the inside of the fuel. A large number of bubble nuclei begin to expand to form large bubbles; that is, cavitation occurs, and the holes in the hole diffuse to different degrees downstream according to the location of each hole.

When the needle valve is fully opened, as the camshaft rotation angle increases, the cavity area inside each hole gradually increases. However, due to the different position distribution of each hole, the increasing speed of each hole cavity area is also different. The cavity area inside holes 3 and 4 increases relatively fast with the camshaft rotation angle, which results in a thicker cavity layer. At the same time, the fuel flow rate of holes 3 and 4 is larger, which is beneficial to the fuel at the nozzle outlet, i.e., atomization, but the effective flow area of the fluid in the hole is small, and the injection rate of the nozzle outlet is lower; the cavity area in the hole 1 increases slowly with the increase of the camshaft angle, and the thickness of the cavity layer is thinner and the fuel flow rate at the outlet of the hole is relatively low. Compared with hole 3 and hole 4, the fuel atomization effect will be affected. However, due to the larger effective flow area in hole 1, the fuel injection rate of hole 1 is relatively high; the growth rate of the internal cavity area is between the above two as the camshaft rotation angle increases.

Under the same hole with different camshaft angles, the high flow rate area inside the hole shows an overall upward trend with the increase of the camshaft angle. This is because for the mechanical pump-pipe-nozzle, the injection pressure gradually rises to the maximum. The rapid increase of inlet pressure promotes the rapid increase of flow velocity in the nozzle. As the cam angle increases, the needle valve is about to be seated, causing the injection pressure to drop rapidly, and the rapid drop in inlet pressure causes a rapid drop in the flow rate inside the nozzle. However, the rapid drop in fuel injection pressure promotes the growth of cavitation bubbles inside the hole, which leads to inconsistent changes in the cavity inside the nozzle and the flow velocity at the end of the injection. Under the same camshaft rotation angle and different holes, the size and distribution of the internal flow velocity of each hole are also different. The high flow velocity areas of holes 3 and 4 develop faster along the bottom of the nozzle. The high-velocity areas of holes 2 and 5 at the inlet of the nozzle are mainly distributed at the bottom of the nozzle. When the fluid flows to the outlet of the nozzle, the highvelocity area is mainly distributed on the central axis of the nozzle. In hole 1, the high-velocity area at the inlet of the nozzle is mainly distributed in the center of the nozzle. When the fluid flows to the outlet of the nozzle, the highvelocity area is basically distributed on the top of the nozzle. It can be seen that the flow velocity distribution at the outlet of the nozzle directly affects the development of the spray, and the study of the fuel flow velocity distribution inside the nozzle is beneficial to the reasonable distribution of the positions of the injector holes.

It can be seen from Figure 3(a) that when the fuel injection volume per cycle is $35 \mathrm{~mm}^{3} / \mathrm{cyc}$, as the cam speed 
TABLE 1: Performance parameters of piezoelectric force sensor.

\begin{tabular}{lcccccc}
\hline $\begin{array}{l}\text { Range } \\
(\mathrm{N})\end{array}$ & $\begin{array}{c}\text { Natural frequency } \\
(\mathrm{kHz})\end{array}$ & $\begin{array}{c}\text { Temperature effect on zero } \\
\left(\% /{ }^{\circ} \mathrm{C}\right)\end{array}$ & $\begin{array}{c}\text { Linearity } \\
(\%)\end{array}$ & $\begin{array}{c}\text { Repeatability }(\% \\
\mathrm{FS})\end{array}$ & $\begin{array}{c}\text { Medium temperature } \\
\left({ }^{\circ} \mathrm{C}\right)\end{array}$ & $\begin{array}{c}\text { Quality } \\
(\mathrm{g})\end{array}$ \\
\hline $0 \sim 10$ & $\geq 40$ & $\leq 0.02$ & $\leq 0.1$ & $\leq 0.1$ & $-30 \sim 80$ \\
\hline
\end{tabular}

TABle 2: Performance parameters of clamp-on pressure sensor.

\begin{tabular}{lcccc}
\hline Range $(\mathrm{MPa})$ & Precision $(\% \mathrm{FS})$ & Temperature effect on zero $\left(\% /{ }^{\circ} \mathrm{C}\right)$ & Operating temperature $\left({ }^{\circ} \mathrm{C}\right)$ & Overpressure range $(\%)$ \\
\hline $0 \sim 180$ & 1 & $\leq 0.02$ & $-30 \sim 120$ & 120 \\
\hline
\end{tabular}

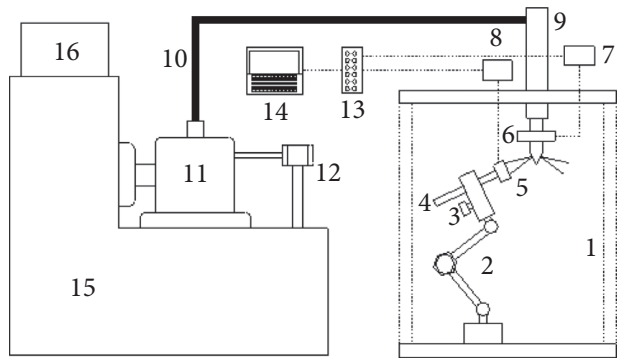

FIgUre 1: Test schematic. 1, oil mist elimination device; 2, magnetic table; 3 , angle adjusting knob; 4 , distance adjusting screw; 5 , force sensor; 6, pressure sensor; 7, sensor amplifier; 8, sensor amplifier; 9 , injector; 10-11, high-pressure tubing; high-pressure pump; 12, oil regulator 13, data acquisition; 14, computer monitoring; 15, pump test bed; 16, pump test bench.

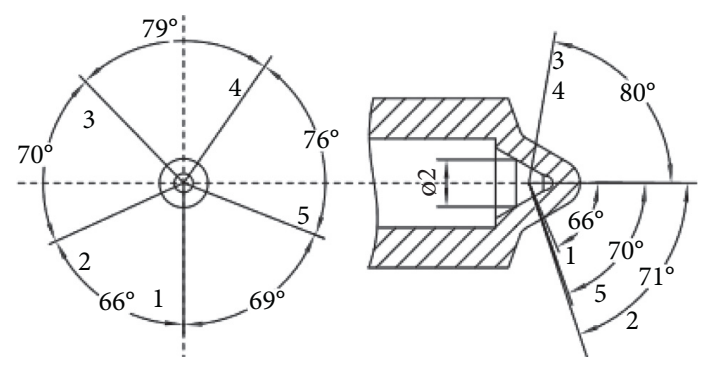

Figure 2: Hole location and parameter diagram.

increases from $800 \mathrm{r} / \mathrm{min}$ to $1200 \mathrm{r} / \mathrm{min}$, the average cycle fuel injection volume of each injector differs by $3.5 \%-9.6 \%$. Hole 1 with the largest average circulating fuel injection rate is $18.4 \%-47.5 \%$ higher than that of the smallest hole 2 . Hole 4 of the No. 4 injector with the maximum average circulating fuel injection amount is $9 \%$ higher than hole 4 of the No. 2 injector; hole 2 of the No. 1 injector with the minimum average circulating fuel injection amount is higher than that of the No. 3 injector. Hole 2 increased by $24 \%$.

It can be seen from Figure 3(b) that when the cam speed is $1000 \mathrm{r} / \mathrm{min}$, as the fuel injection volume per cycle increases from $35 \mathrm{~mm}^{3} /$ cyc to $55 \mathrm{~mm}^{3} / \mathrm{cyc}$, the average cycle fuel injection volume of each injector differs by $0.3 \%-5.5 \%$. Hole 1 with the largest average circulating fuel injection rate is $12.9 \%-36 \%$ higher than that of the smallest hole 2 . Hole 4 of the No. 4 injector with the maximum average circulating fuel injection amount is $1.1 \%$ higher than that of the No. 2 injector; hole 2 of the No. 1 injector with the minimum average circulating fuel injection is higher than that of the No. 3 injector. Hole 2 increased by $20.3 \%$.

The transient flow coefficient is a changing curve, for the convenience of comparative analysis. The average flow coefficient of each hole is analyzed for comparison when the needle of the injector is fully open.

As shown in Figure 4(a), under the same rack position, the flow coefficients of each hole of four injectors change when the pump camshaft rotation speed changes. As shown in Figure 4(b), under the same rotation speed, when the needle is fully open, the flow coefficients of each hole of four injectors change when the pump cycle injection quantity changes. Under each different operating condition, when the needle is fully open, the flow coefficient of each hole of four injectors is $\overline{C_{d 1}}>\overline{C_{d 4}}>\overline{C_{d 3}}>\overline{C_{d 5}}>\overline{C_{d 2}}$, the trend of which is in line with the cycle injection quantity of each hole.

It can be seen from Figure 4(a) that when the fuel injection volume per cycle is $35 \mathrm{~mm}^{3} / \mathrm{cyc}$, as the cam speed increases from $800 \mathrm{r} / \mathrm{min}$ to $1200 \mathrm{r} / \mathrm{min}$, the average flow coefficient of each injector differs by $1.4 \%-5.7 \%$. Hole 1 with the largest average flow coefficient is $17.9 \%-30 \%$ higher than that of the smallest hole 2. Hole 4 of the No. 4 injector with the maximum average flow coefficient is $3.8 \%$ higher than that of the No. 2 injector; hole 2 of the No. 1 injector with the minimum average flow coefficient is higher than hole 2 of the No. 3 injector. That is $11.6 \%$.

It can be seen from Figure 4(b) that when the cam speed is $1000 \mathrm{r} / \mathrm{min}$, as the fuel injection volume per cycle increases from $35 \mathrm{~mm}^{3} /$ cyc to $55 \mathrm{~mm}^{3} / \mathrm{cyc}$, the average flow coefficient of each injector differs by $2.8-4.2 \%$. Hole 1 with the largest average flow coefficient is $16.1 \%-28.7 \%$ higher than that of the smallest hole 2. Hole 4 of the No. 4 injector with the maximum average flow coefficient is $2.5 \%$ higher than that of the No. 2 injector; hole 2 of the No. 1 injector with the minimum average flow coefficient is higher than hole 2 of the No. 3 injector, $9.8 \%$.

\subsection{Injector Injection Pressure and Injection Characteristics of} Each Hole. Under the same operating conditions, each orifice is tested 100 times and the average parameters are recorded.

Figure 5 represents the No. 4 actual injection pressure, the spray momentum of each hole, the injection rate, and the transient flow coefficient as the camshaft rotation angle changes (to reduce the length of this paper, the figures for the remaining similar operating conditions will not be listed). 

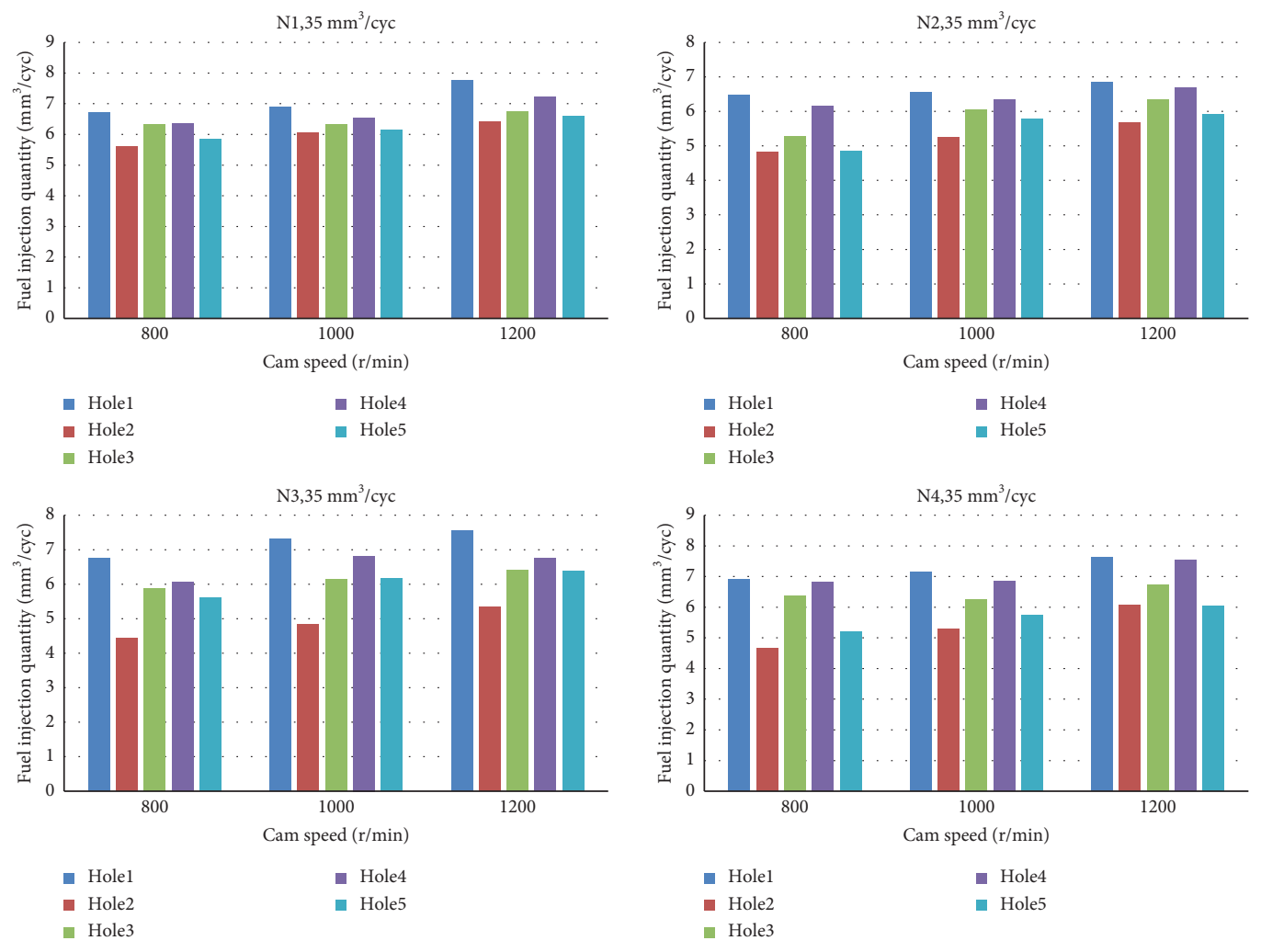

(a)
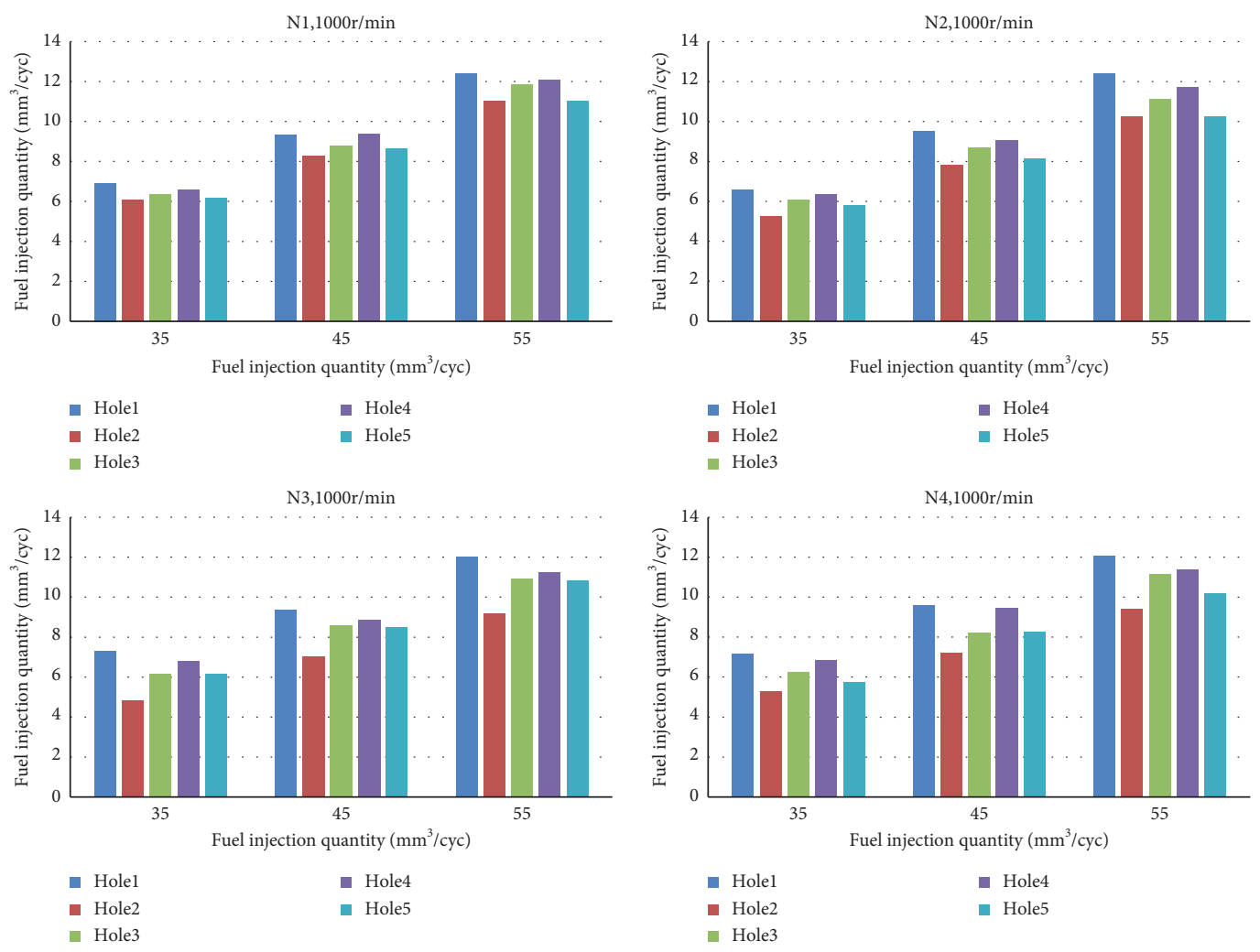

(b)

FIGURE 3: The fuel cycle injection quantity of each hole of four injectors. (a) The cycle injection quantity is $35 \mathrm{~mm} / \mathrm{cyc}$ when the speed of rack position is $1000 \mathrm{r} / \mathrm{min}$. (b) Different rack positions when the camshaft rotation speed is $1000 \mathrm{r} / \mathrm{min}$. 

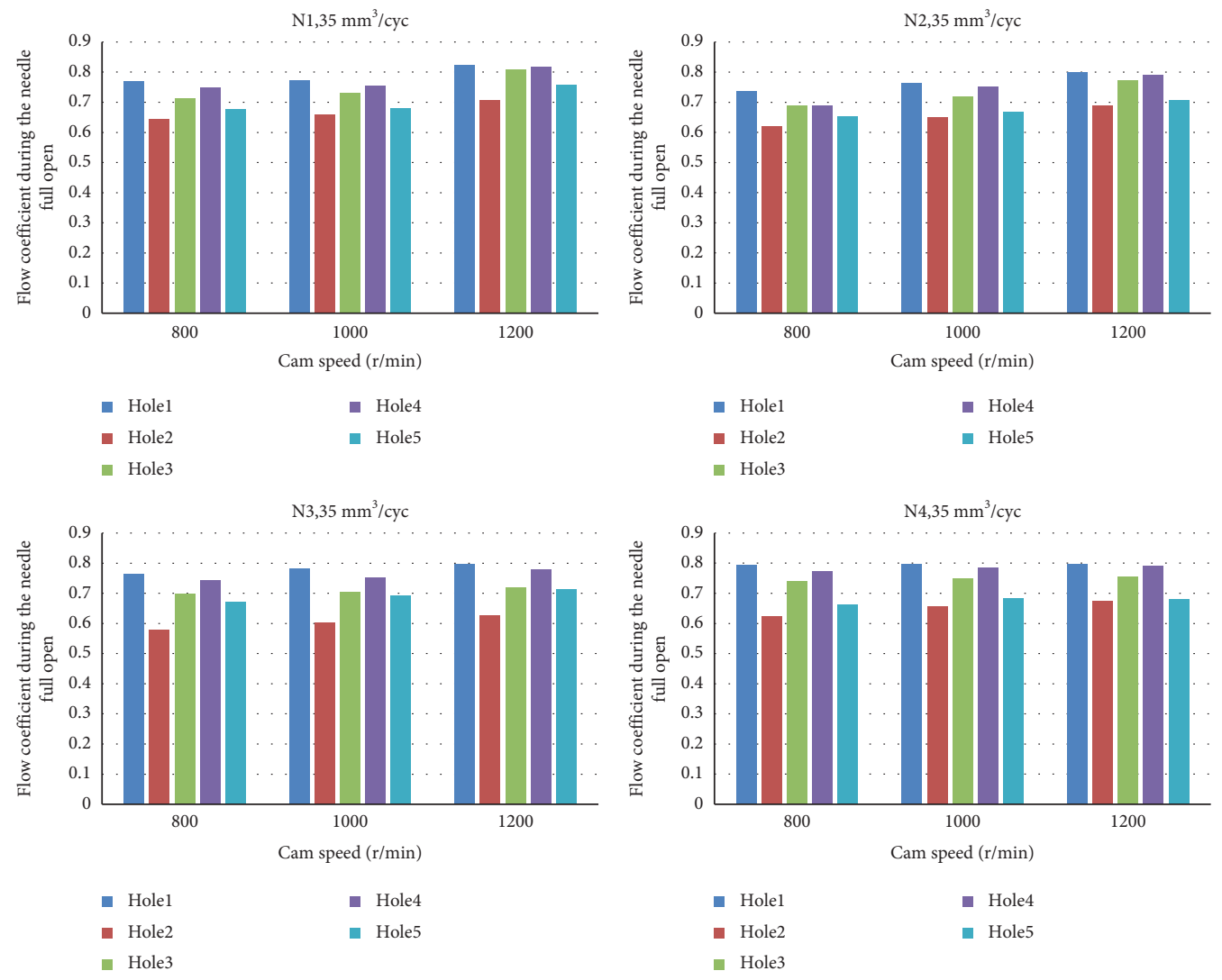

(a)
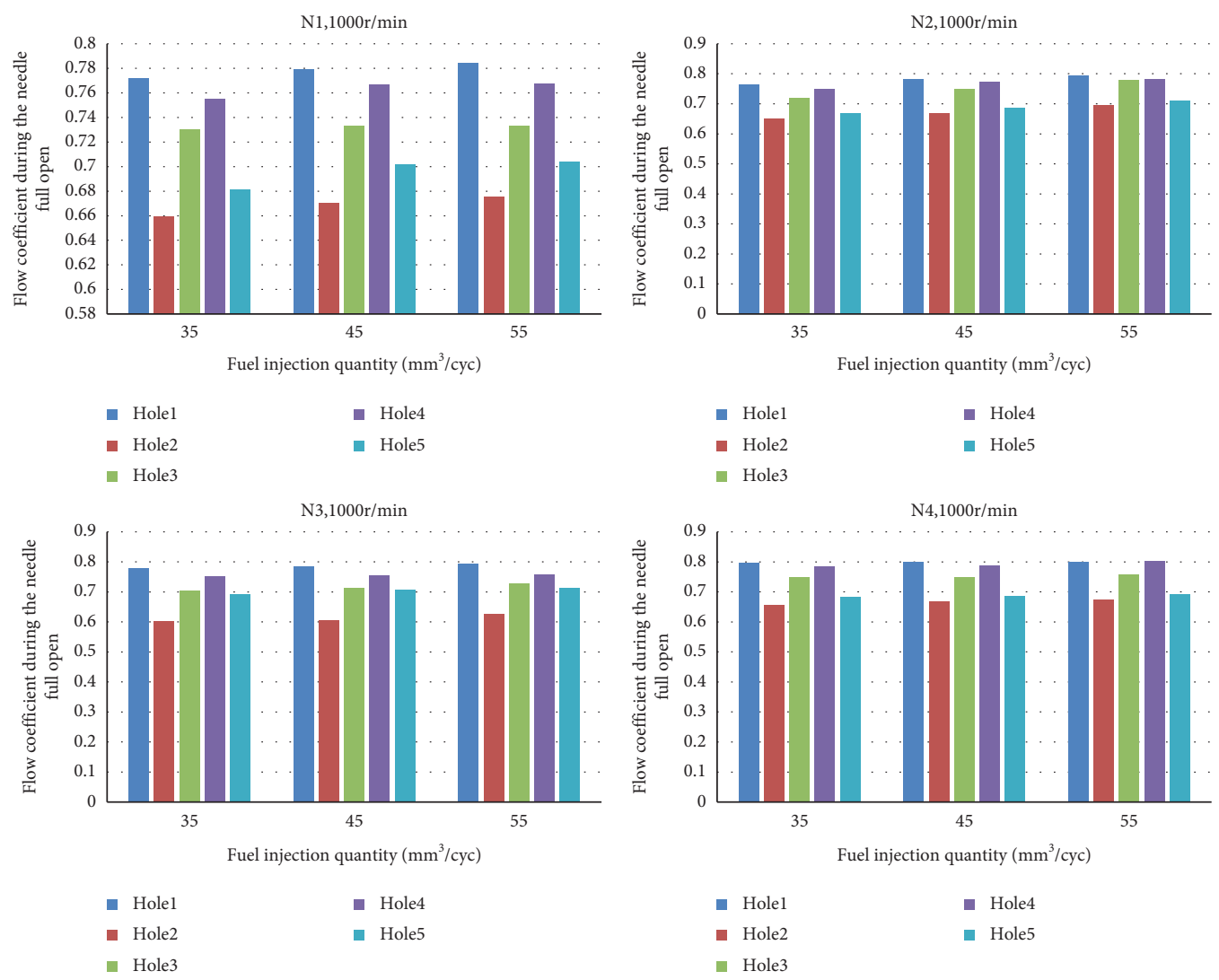

(b)

FIGURE 4: The flow coefficient of each hole when the needles of the injectors are full open. (a) The cycle injection quantity is $35 \mathrm{~mm}^{3} / \mathrm{cyc}$ when the speed of rack position is $1000 \mathrm{r} / \mathrm{min}$. (b) Different rack positions when the camshaft rotation speed is $1000 \mathrm{r} / \mathrm{min}$. 

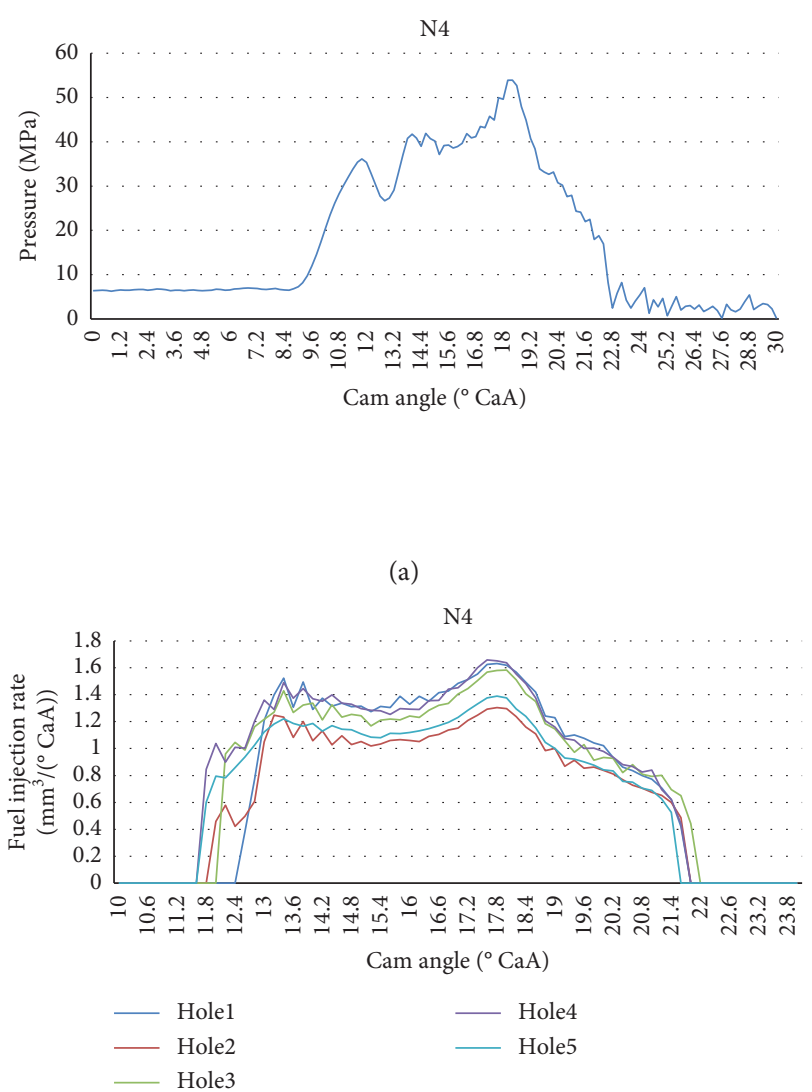

(c)

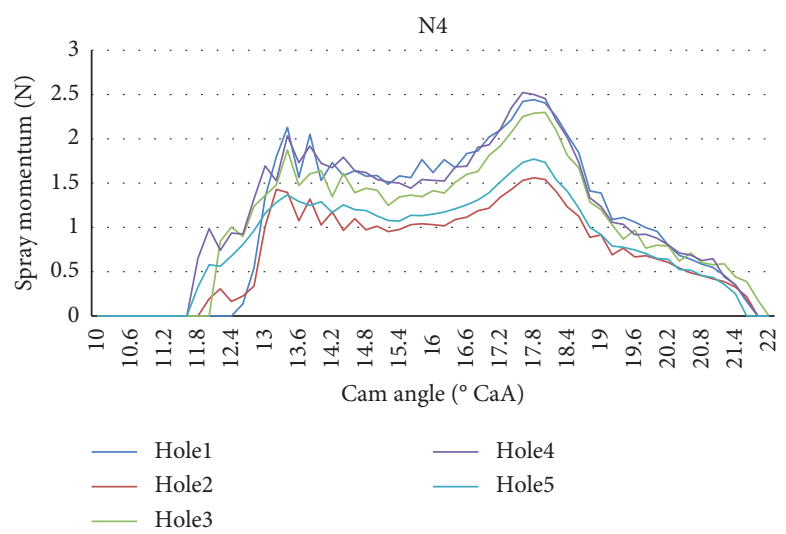

(b)

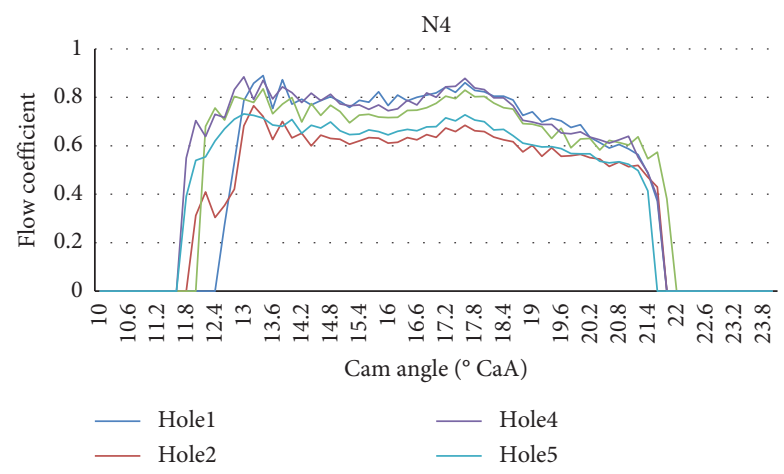

(d)

FIGURE 5: The injection pressure, spray momentum, fuel injection rate, and dynamic coefficient of each hole at $1000 \mathrm{r} / \mathrm{min}, 55 \mathrm{~mm} \mathrm{~m}^{3} / \mathrm{cyc}$. (a) Injection pressure, (b) spray momentum of each hole, (c) injection rate of each hole, and (d) transient flow coefficient of each hole.

The curves for each hole are similar, but there remain some differences. There are also some differences among the injection rate determined by equation (4) and the transient flow coefficient of each hole determined by equation (6). In the same injector, the main reasons for the differences existing in the cycle injection quantity of each hole are as follows: nominally, the size of each hole is the same, but there are some deviations on the surface during the spray process; the angles between each hole and the needle axis are different; and there is a certain distance between the needle guide part and the head, which is so close to the nozzle. There is also some kind of eccentricity during the process of needle rising. Hence, some of the holes inject first and some second. As a result, there are differences in the injection rate between holes [27].

3.3. The Total Dynamic Flow Coefficient of Each Hole of the Injector. In terms of the transient flow coefficient of each hole, the total coefficient is obtained with equation (7). Figure 6 shows the total flow coefficient of the No. 4 injector under the different pump camshaft rotation.

In Figure 6(a), with different speeds under the same rack position, the flow coefficients of all the holes change dynamically as the pump camshaft rotation angle changes. The total dynamic flow coefficient of each hole is roughly the same as the change of the fuel injection pattern. When the fuel injection volume per cycle is $35 \mathrm{~mm}^{3} / \mathrm{cyc}$, as the speed of the fuel injection pump increases from $800 \mathrm{r} / \mathrm{min}$ to $1200 \mathrm{r} /$ min, the duration of the total dynamic flow coefficient of each orifice at each speed increases from $6.4^{\circ}$ to $7.6^{\circ}$ and $8.4^{\circ}$. The discharge coefficient during the spraying period also increased by $8.4 \%$ and $10 \%$, respectively, gradually changing from a triangle-like pattern to a rectangular-like pattern. This is because as the speed increases, the unit cam angle meter time decreases, the fuel pressure increases faster, and the fuel supply capacity of the fuel injection pump increases.

In Figure 6(b), with the same speed under different rack positions, the flow coefficients of all the holes change as the pump camshaft rotation angle is dynamic. When the cam speed is $1000 \mathrm{r} / \mathrm{min}$, as the fuel injection volume increases from $35 \mathrm{~mm}^{3} / \mathrm{cyc}$ to $55 \mathrm{~mm}^{3} / \mathrm{cyc}$, the duration of the total dynamic flow coefficient of each orifice at each speed increases from $7.4^{\circ}$ to $9^{\circ}$ and $10.4^{\circ}$. During the main spray, the discharge coefficients have also increased by $2.8 \%$ and $12.8 \%$, respectively, gradually changing from a triangle-like shape to a trapezoid-like figure.

3.4. The Uniformity of the Circulating Fuel Injection Volume and Flow Coefficient of Each Hole of the Fuel Injector. As for the hole, due to the errors in the size, shape, and surface 


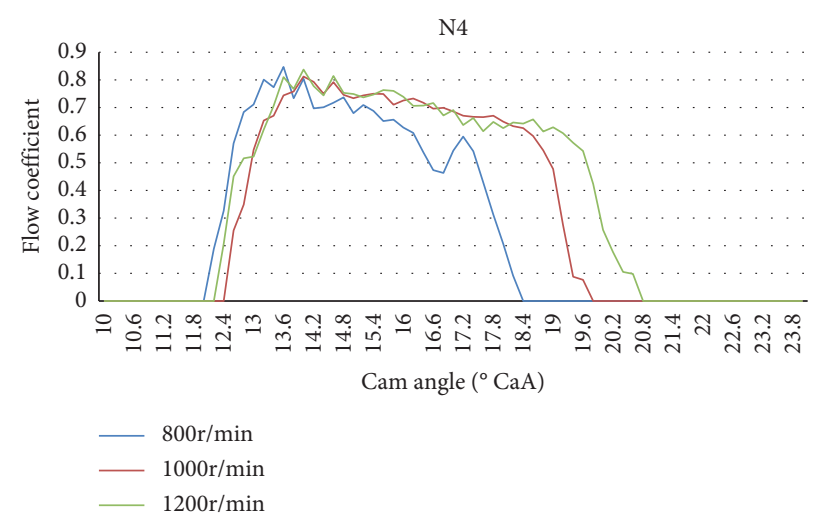

(a)

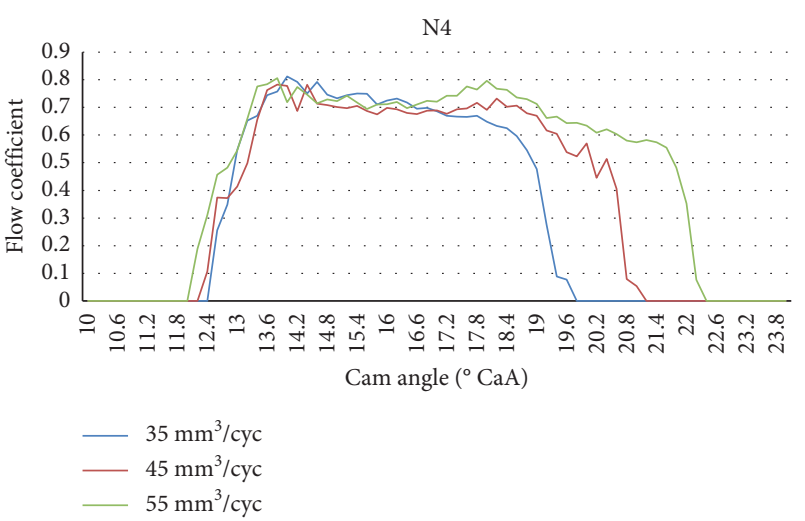

(b)

Figure 6: The total transient flow coefficients of each hole in the injector. (a) When the speed of the rack position is $1000 \mathrm{r} / \mathrm{min}$, the cycle injection quantity is $35 \mathrm{~mm}^{3} / \mathrm{cyc}$. (b) Different rack positions when the camshaft rotation speed is $1000 \mathrm{r} / \mathrm{min}$.

quality and some burr problems, there are some differences among the flow coefficient of each hole in the same model that affect the injector performance. To analyze the cycle injection quantity and the uniformity of the flow coefficient, the relative parameter $X_{R i}$ is defined and the nonuniformity $\delta_{x}$ is shown as follows:

$$
\begin{aligned}
X_{R i} & =\frac{X_{i}}{X_{m}} \\
\delta_{x} & =\frac{\left(X_{\max }-X_{\min }\right)}{X_{m}} \times 100 \% .
\end{aligned}
$$

In the equations, $X_{i}$ represents the parameters of the NO.i hole; $X_{\max }$ refers to the largest; $X_{\min }$, the smallest; and $X_{m}$, the average.

$X_{R i}$ reflects the comparison value of each hole with other average values. $\delta_{x}$ reflects the largest percentage of each hole with other average values.

The nonuniformity is one of the characteristic parameters of the injection consistency between the injector holes of the porous diesel engine. It can be known from the relative fuel injection amount shown in the formula and the definition of the nonuniformity shown in the formula, which describes the relative fuel injection of all injection holes, the largest difference between the amounts. To a certain extent, the larger the nonuniformity coefficient, the worse the consistency of spraying between holes.

Figure 7(a) shows that, under the same rack position, the relative cycle injection quantity of each hole and nonuniformity change as the rotation speed changes. The nonuniformity of the No. 1 injector has been reduced from $17.8 \%$ to $11.8 \%$. The nonuniformity of the No. 2 injector was reduced from $29.8 \%$ to $18.4 \%$. The nonuniformity of the No. 3 injector was reduced from $40.8 \%$ to $34 \%$. The nonuniformity of the No. 4 injector was reduced from $37.7 \%$ to $23.1 \%$.

Figure 7(b) shows the changes in the cycle injection quantity of each hole of four injectors and the nonuniformity under the same pump rotation speed. As the injection quantity increases, the nonuniformities of the injection quantity of each hole decrease. The nonuniformity of the No. 1 injector was reduced from $13.4 \%$ to $11.6 \%$. The nonuniformity of the No. 2 injector was reduced from $22.1 \%$ to $19.2 \%$. The nonuniformity of the No. 3 injector is reduced from $39.3 \%$ to $34 \%$. The nonuniformity of the No. 4 injector was reduced from $29.5 \%$ to $24.4 \%$.

Figure 8 (a) shows that, under the same rack position, when the needle is fully open, the relative flow coefficients and nonuniformities of each hole of the four injectors change as the pump rotation speed changes. The nonuniformities among the flow coefficient of each injector hole decrease as the rotation speed increases. Figure 8(b) shows that, under the same rotation speed, when the needle is fully open, the relative flow coefficient and nonuniformity of each hole change as the pump cycle fuel injection quantity changes. The nonuniformity of each injector hole decreases as the cycle fuel injection quantity increases. Under each operating condition, the nonuniformity of the No. 3 injector is the largest; No. 4 is the second; and No. 1 and No. 2 are relatively small. Under each operating condition, when the needle is fully open, the relative flow coefficient and nonuniformity of each hole of No. 1 and No. 4 are the largest; No. 2 and No. 5 are relatively small. The nonuniformities among each hole are large. The flow coefficients of No. 1 and No. 5 are larger than the average coefficient of the other holes, while No. 2 and No. 5 are smaller, whose changing tendency is the same as that of the cycle fuel injection quantity of each hole. However, the changes in the relative flow coefficient and nonuniformity of each hole are smaller than those of the relative cycle fuel injection and nonuniformity. All of these findings indicate that when the needle is fully open, the flow coefficient of each hole could not fully reflect the characteristics of the whole fuel injection process.

Figure 8 (a) shows the variation of the relative flow coefficient and the nonuniformity of each hole of the four injectors with the speed of the fuel injection pump when the needle valve is fully opened when the circulating fuel injection volume is $35 \mathrm{~mm}^{3} /$ cyc. The nonuniformity between the flow coefficients of each injector orifice gradually 

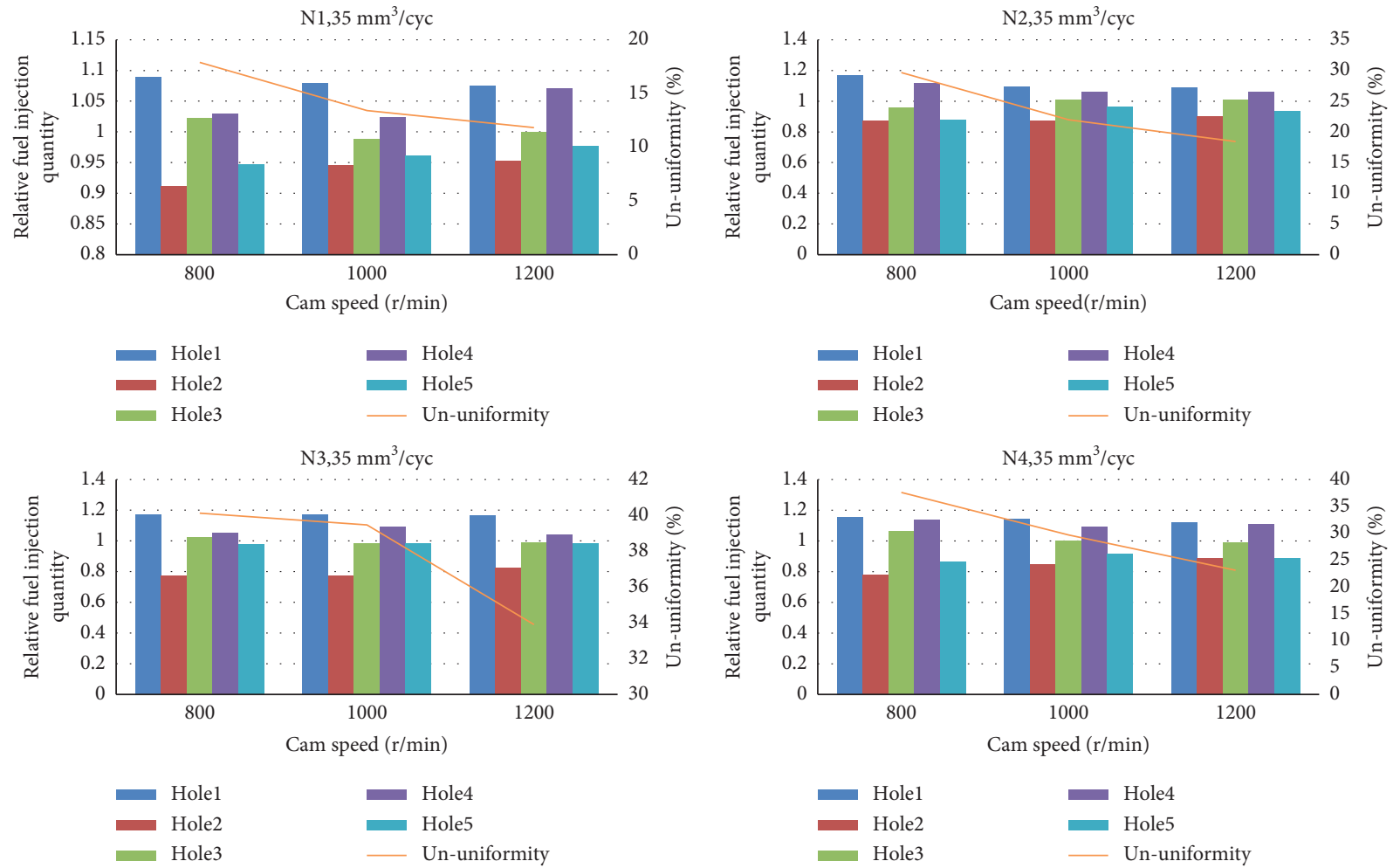

(a)
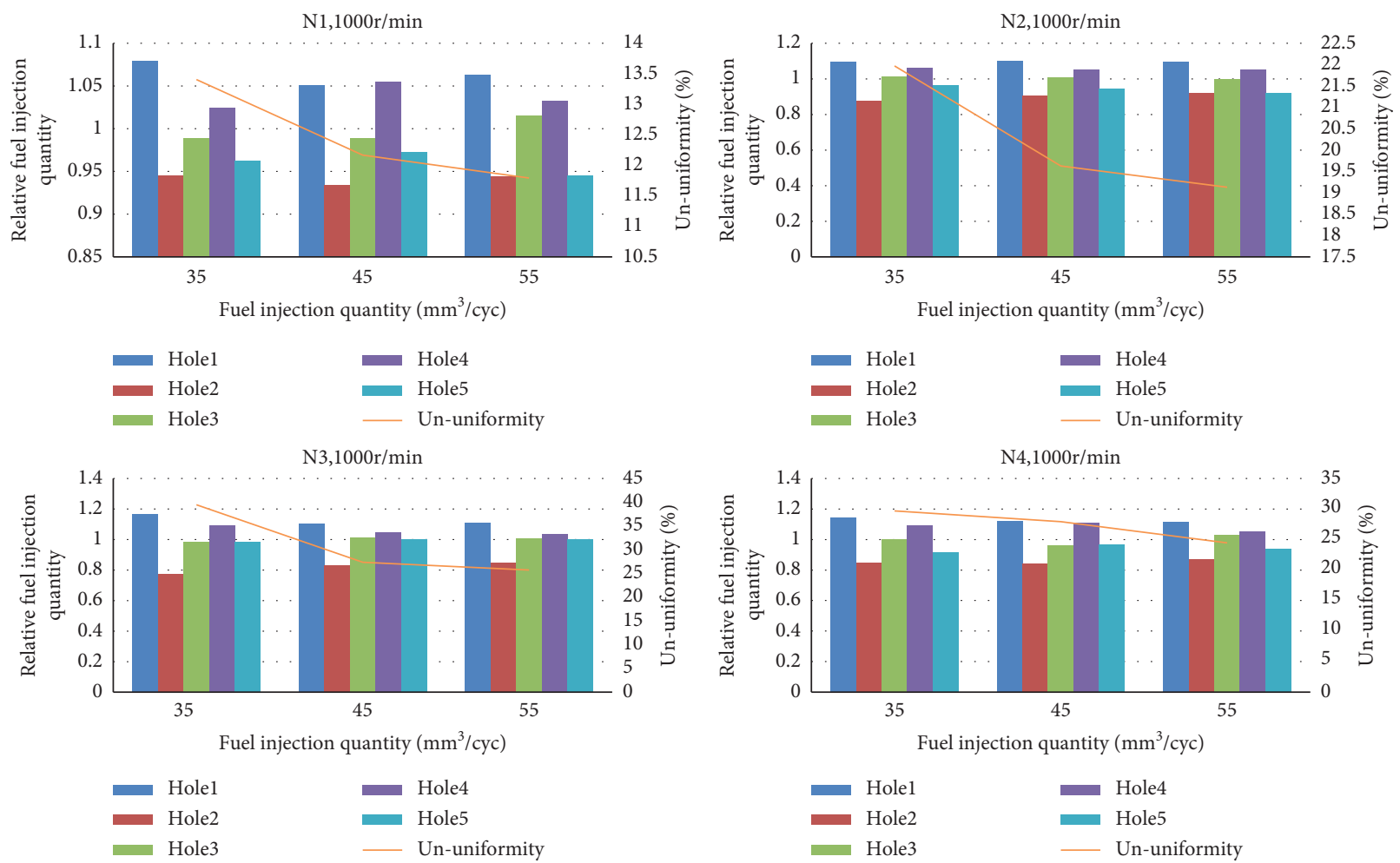

(b)

FIGURE 7: Relative cycle fuel injection and nonuniformities of each hole in four injectors. (a) The cycle injection quantity is $35 \mathrm{~mm}^{3} / \mathrm{cyc}^{\mathrm{c}}$ when the speed of rack position is $1000 \mathrm{r} / \mathrm{min}$. (b) Different rack positions when the camshaft rotation speed is $1000 \mathrm{r} / \mathrm{min}$. 

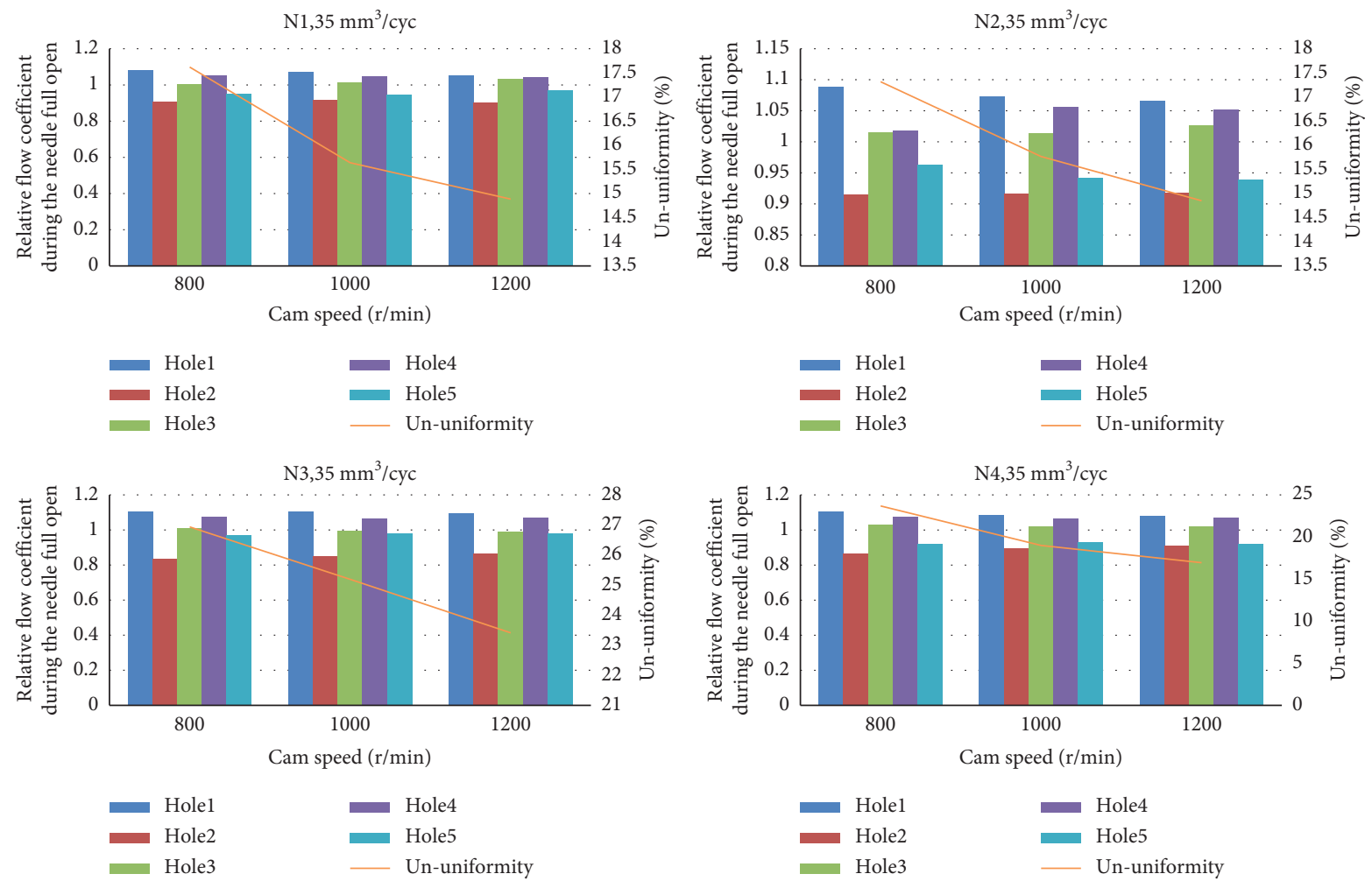

(a)
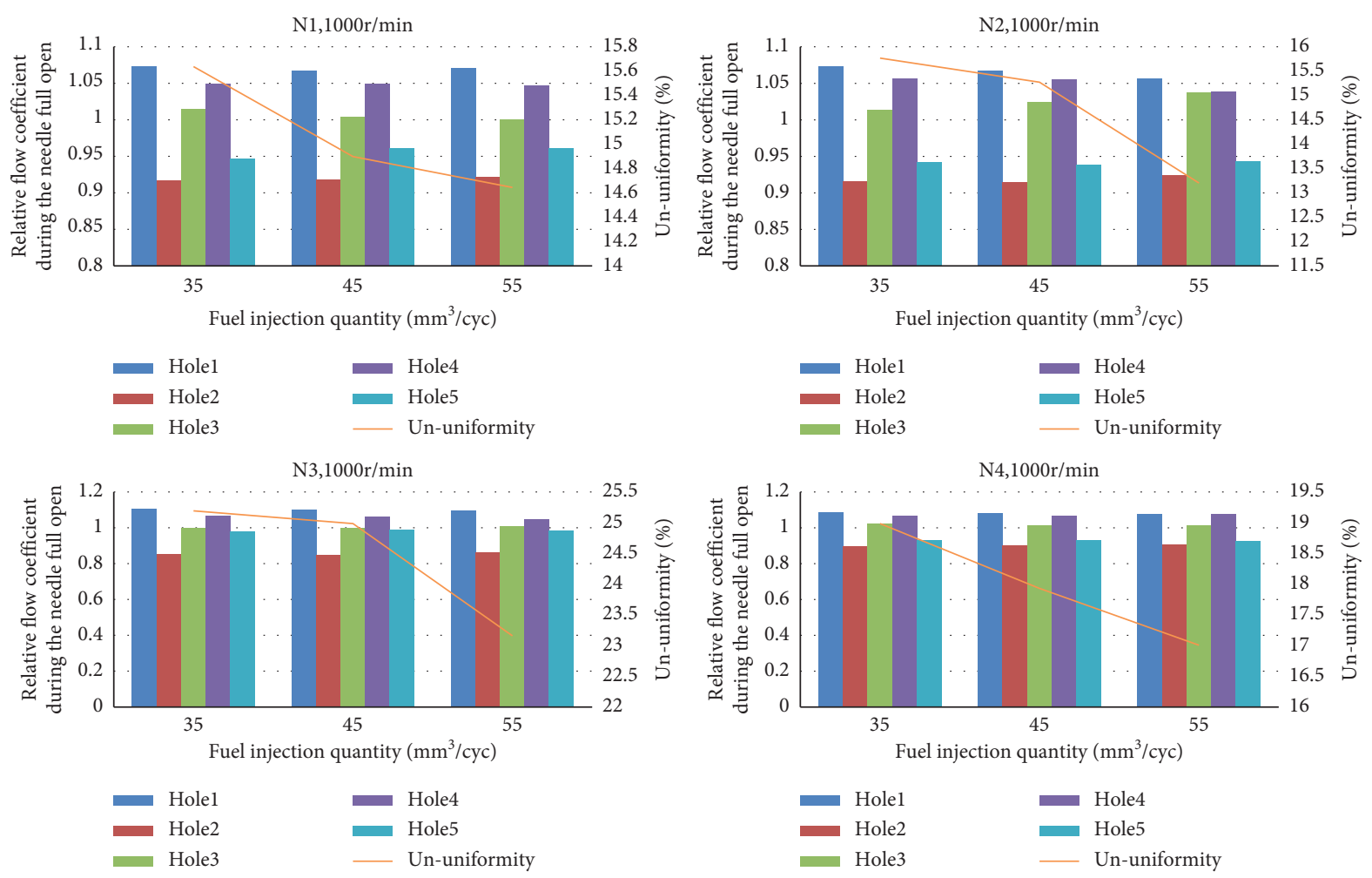

(b)

FIGURE 8: Relative flow coefficient of each hole and nonuniformity when the needle is full open. (a) The cycle fuel injection quantity is $35 \mathrm{~mm}^{3} / \mathrm{cyc}$ when the speed of rack position is $1000 \mathrm{r} / \mathrm{min}$. (b) Different rack positions when the camshaft rotation speed is $1000 \mathrm{r} / \mathrm{min}$. 
decreases with the increase of speed. The nonuniformity of the No. 1 injector was reduced from $17.6 \%$ to $14.7 \%$. The nonuniformity of the No. 2 injector was reduced from $17.3 \%$ to $14.8 \%$. The nonuniformity of the No. 3 injector has been reduced from $27 \%$ to $23.4 \%$. The nonuniformity of the No. 4 injector was reduced from $23.8 \%$ to $16.9 \%$.

Figure 8 (b) shows the relative flow coefficient and nonuniformity of each injector hole with the fuel injection pump circulating fuel injection volume when the needle valve is fully opened when the fuel injection pump speed is $1000 \mathrm{r} / \mathrm{min}$. The uneven degree gradually decreases with the increase of circulating fuel injection. The nonuniformity of the No. 1 injector was reduced from $15.7 \%$ to $14.6 \%$. The nonuniformity of the No. 2 injector was reduced from $15.7 \%$ to $13.1 \%$. The nonuniformity of the No. 3 injector is reduced from $25.2 \%$ to $23.2 \%$. The nonuniformity of the No. 4 injector has been reduced from $19 \%$ to $17 \%$.

Under each working condition, for the nonuniformity of the flow coefficient among the holes of the four injectors, the No. 3 injector is the largest, the No. 4 injector is the second, and the No. 1 and No. 2 injectors are smaller. Under various working conditions, when the injector needle valve is fully opened, for the relative flow coefficient of each hole and the flow coefficient of each hole, No. 1 and No. 4 holes are larger, and No. 2 and No. 5 holes are smaller. The nonuniformity between each hole is larger, the flow coefficients of the No. 1 and No. 4 holes are greater than the average value between the holes, and the No. 2 and No. 5 holes are smaller than the average value between the holes, and the change trend is the same as the change of the circulating fuel injection volume of each hole. The relative flow coefficient difference of each hole is between 0 and 0.02 , and the nonuniformity difference is between $1.8 \%$ and $16.9 \%$, and the relative circulating fuel injection amount difference of each hole is between 0.02 and 0.1 , and its nonuniformity difference is between $1.1 \%$ and $6.9 \%$. The relative flow coefficient of each hole and its nonuniformity are smaller than the relative circulating fuel injection volume of each hole and its nonuniformity.

\section{Conclusion}

The article uses an improved momentum method to conduct spray experiments on each hole of four injectors of the same model. Conclusion is as follows:

(1) Test the injection pressure and spray momentum of each hole of the fuel injector, and obtain the transient flow coefficient of each hole, as well as the injection rate and circulating injection volume. A standard for evaluating the relative quality of injectors based on the average circulating fuel injection volume, average flow coefficient, and nonuniformity is put forward. It has a certain guiding effect on the processing, measurement, and evaluation of fuel injectors.

(2) The circulating fuel injection volume and flow coefficient of each hole of the same injector are different. When the fuel injection volume per cycle is $35 \mathrm{~mm}^{3} /$ cyc, as the speed of the fuel injection pump increases from $800 \mathrm{r} / \mathrm{min}$ to $1200 \mathrm{r} / \mathrm{min}$, the average cycle fuel injection volume varies by $2.8 \%-47.5 \%$; the average flow coefficient varies by $3.7 \%-30 \%$; when the cam speed is $1000 \mathrm{r} / \mathrm{min}$, as the fuel injection volume increases from $35 \mathrm{~mm}^{3} /$ cyc to $55 \mathrm{~mm}^{3} /$ cyc, the average circulating fuel injection volume of each injector differs by $1.8 \%-36 \%$, and the average flow coefficient differs by $2.5 \%-28.7 \%$.

(3) The circulating fuel injection volume and flow of different fuel injectors of the same model are different. When the fuel injection volume per cycle is $35 \mathrm{~mm}^{3} / \mathrm{cyc}$, as the speed of the fuel injection pump increases from $800 \mathrm{r} / \mathrm{min}$ to $1200 \mathrm{r} / \mathrm{min}$, the average cycle fuel injection volume of each injector differs by $3.5 \%-9.6 \%$, and the average flow coefficient differs by $1.4 \%-5.7 \%$; when the cam speed is $1000 \mathrm{r} / \mathrm{min}$, as the fuel injection volume increases from $35 \mathrm{~mm}^{3} /$ cyc to $55 \mathrm{~mm}^{3} / \mathrm{cyc}$, the average circulating fuel injection volume of each injector differs by $0.3 \%-5.5 \%$, and the average flow coefficient differs by $2.8-4.2 \%$.

(4) The flow coefficient of each hole of the injector changes dynamically. When the fuel injection volume per cycle is $35 \mathrm{~mm}^{3} / \mathrm{cyc}$, as the speed of the fuel injection pump increases from $800 \mathrm{r} / \mathrm{min}$ to $1200 \mathrm{r} /$ min, the duration of the total dynamic flow coefficient of each orifice at each speed increases from $6.4^{\circ}$ to $7.6^{\circ}$ and $8.4^{\circ}$. The discharge coefficient during the spray period also increased by $8.4 \%$ and $10 \%$, respectively. When the cam speed is $1000 \mathrm{r} / \mathrm{min}$, as the fuel injection rate increases from $35 \mathrm{~mm}^{3} / \mathrm{cyc}$ to $55 \mathrm{~mm}^{3} /$ cyc, the duration of the total dynamic flow coefficient of each orifice at each speed increases from $7.4^{\circ}$ to $9^{\circ}$ and $10.4^{\circ}$. During the main injection period, the flow coefficients of the products have also increased by $2.8 \%$ and $12.8 \%$, respectively.

(5) The circulating fuel injection volume of each hole of the fuel injector increases with the increase of the fuel injection pump speed and the circulating fuel injection volume, and its nonuniformity decreases. The injection hole with a large flow coefficient has a large circulating fuel injection volume. The relative flow coefficient difference of each hole is between 0 and 0.02 , and the nonuniformity difference is between $1.8 \%$ and $16.9 \%$, and the relative circulating fuel injection amount difference of each hole is between 0.02 and 0.1 , and its nonuniformity difference is between $1.1 \%$ and $6.9 \%$, and the relative flow coefficient and nonuniformity of each hole are smaller than the relative circulating fuel injection volume and nonuniformity of each hole.

\section{Data Availability}

The data used to support the findings of this study are available from the corresponding author (250930192@ qq.com) upon request .

\section{Conflicts of Interest}

The authors declare that they have no conflicts of interest. 


\section{Acknowledgments}

This work was supported by Postgraduate Research and Practice Innovation Program of Jiangsu Province References (KYCX17_1777).

\section{References}

[1] L. B. Zhou, Z. C. Liu, and Z. Y. Gao, Internal Combustion Engine, China Machine Press, Beijing, China, 2010.

[2] O. Armas and C. Mata, "Effect of diesel injection parameters on instantaneous fuel delivery using a solenoid operated injector with different fuels," Revista Facultad De Ingeniería Universidad De Antioquia, vol. 20, no. 64, pp. 9-21, 2012.

[3] B.-S. Kim, K.-D. Kim, W.-H. Yoon, and S.-H. Ryu, "Experimental study on the effects of injector nozzle and piston bowl geometry on combustion and performance in medium-speed diesel engines," in Proceedings of the ASME 2007 Internal Combustion Engine Division Fall Technical Conference, Charleston, SC, USA, October 2007.

[4] J. Zhang, G. Y. Li, and Y. Yuan, "Numerical simulation and analysis of the influence of fuel injection rate-shape on diesel engine combustion process," Acta Armamentarii, vol. 33, no. 3, pp. 347-353, 2012.

[5] L. M. Shao, H. B. Chang, J. D. Zhou, H.-J. Jin, and W.-J. Shi, "Study on influence of nozzle geometric parameters on injection characteristic of multi-hole injector," Chinese Internal Combustion Engine Engineering, vol. 31, no. 6, pp. 43-48, 2010.

[6] J. D. Yu, X. L. Miao, W. Yang, and Y.-Y. Zhang, "Study on effected factor and injection characteristics of nozzle flow coefficient," Modern Vehicle Power, vol. 3, pp. 19-23, 2007.

[7] J. F. Fang, H. Y. Du, J. X. Liu, M. Li, Y.-P. Zong, and F. Wang, "Effect of flow coefficient on fuel spray and diesel engine performance," Journal of Henan University of Science and Technology: Natural Science, vol. 25, no. 2, pp. 24-27, 2004.

[8] M. Marčič, "A new method for measuring fuel-injection rate," Flow Measurement and Instrumentation, vol. 10, no. 3, pp. 159-165, 1999.

[9] M. Marčič, "Measuring method for diesel multi-hole injection nozzles," Sensors and Actuators A: Physical, vol. 107, no. 2, pp. 152-158, 2003.

[10] Y. Amin, M. Birouk, and H. Guo, "An experimental and numerical study of the effect of diesel injection timing on natural gas/diesel dual-fuel combustion at low load," Fuel, vol. 203, pp. 642-657, 2017.

[11] Y. L. Wu, J. Tang, and X. Lan, "Design of the testing system of the new type diesel engine fuel injection regulation," Journal of Agricultural Mechanization Research, vol. 6, pp. 203-204, 2007.

[12] J. Benajes, R. Payri, S. Molina, and V. Soare, "Investigation of the influence of injection rate shaping on the spray characteristics in a diesel common rail system equipped with a piston amplifier," Journal of Fluids Engineering, vol. 127, no. 6, pp. 1102-1110, 2005.

[13] R. Payri, J. Gimeno, M. Bardi, and A. Plazas, "Effect of injection rate shaping over diesel spray development in non reacting evaporative conditions," vol. 44663, pp. 347-356, 2012.

[14] F. Payri, R. Payri, F. J. Salvador, and J. Gimeno, "Comparison between different hole to hole measurement techniques in a diesel injection nozzle," SAE Technical Papers, 2005.
[15] R. Payri, C. Guardiola, F. J. Salvador, and J. Gimeno, "Critical cavitation number determination in diesel injection nozzles," Experimental Techniques, vol. 28, no. 3, pp. 49-52, 2010.

[16] R. Payri, A. García, V. Domenech, R. Durrett, and A. H. Plazas, "An experimental study of gasoline effects on injection rate, momentum flux and spray characteristics using a common rail diesel injection system," Fuel, vol. 97, pp. 390-399, 2012.

[17] F. J. Salvador, J. J. Lopez, and J. De la Morena, "Experimental investigation of the effect of orifices inclination angle in multihole diesel injector nozzles. Part 1-hydraulic performance," Fuel, vol. 213, pp. 207-214, 2018.

[18] Z. Wang, J. G. Yang, and W. C. Fang, "A calculation method of the fuel injection law for a low-speed high pressure common rail (HPCR) diesel engine," Journal of Harbin Engineering University, vol. 11, pp. 1468-1473, 2011.

[19] D. K. Sangiah and L. C. Ganippa, "Application of spray impingement technique for characterisation of high pressure sprays from multi-hole diesel nozzles," International Journal of Thermal Sciences, vol. 49, no. 2, pp. 409-417, 2010.

[20] F. Payri, V. Bermúdez, R. Payri, and F. J. Salvador, "The influence of cavitation on the internal flow and the spray characteristics in diesel injection nozzles," Fuel, vol. 83, no. 45, pp. 419-431, 2004.

[21] F. J. Salvador, J. Martínez-López, M. Caballer, and C. De Alfonso, "Study of the influence of the needle lift on the internal flow and cavitation phenomenon in diesel injector nozzles by CFD using RANS methods," Energy Conversion and Management, vol. 66, pp. 246-256, 2013.

[22] L. Postrioti, F. Mariani, and M. Battistoni, "Experimental and numerical momentum flux evaluation of high pressure diesel spray," Fuel, vol. 98, pp. 149-163, 2012.

[23] C. Soteriou, R. Andrews, and M. Smith, "Direct injection diesel sprays and the effect of cavitation and hydraulic flip on atomization," Simulation \& Modeling, vol. 120, no. 16, pp. 84-93, 1995.

[24] F. Q. Luo, H. F. Cui, and S. F. Dong, "Momentum method test of the injection regularity of each hole of the porous injector," in Proceedings of the Annual Meeting of Combustion Science of Chinese Society of Engineering Thermophysics, Tianjin, China, 2013.

[25] F. Q. Luo, B. J. Ye, S. F. Dong, and H.-F. Cui, "Measurement analysis on cyclical variation of each hole injection rate of diesel injector," Chinese Internal Combustion Engine Engineering, vol. 36, no. 6, pp. 124-130, 2015.

[26] F. Luo, H. Cui, and S. Dong, "Transient measuring method for injection rate of each nozzle hole based on spray momentum flux," Fuel, vol. 125, pp. 20-29, 2014.

[27] Y. P. Zong, Z. H. Zhao, and B. T. Zhu, "Analysis of the problems existing in the flow of each hole of the fuel injection," Internal Combustion Engine, vol. 4, no. 19-21, p. 59, 2000. 